\title{
Correlation of intraoperative and HRCT of temporal bone findings in CSOM
}

\author{
Pramod $\mathbf{V}^{1^{*}}$, Raghuraj $\mathbf{U}^{2}$, Shrikrishna $\mathbf{U}^{3}$ \\ ${ }^{1}$ Post Graduate, ${ }^{2}$ Professor, ${ }^{3}$ Professor and Head, Dept. of Radiodiagnosis, K.S. Hedge Medical Academy, NITTE University, \\ Mangalore, Karnatak, India \\ *Corresponding Author: Pramod V \\ Email:pram.med29@gmail.com
}

\begin{abstract}
Introduction: The aim of the study was to assess diagnostic role of High Resolution Multi-detector Computed Tomography (HRMDCT) of temporal bone in the evaluation of Chronic Suppurative Otitis Media (CSOM) and to correlate intraoperative and HRCT findings in CSOM in selective cases.

Material and Methods: 57 patients presented with CSOM in ENT department, referred to Radio diagnosis department were included in this study. The suspected patients were subjected to HRCT of Temporal bone using GE Bright speed Elite16 multi slice CT machine with $0.6 \mathrm{~mm}$ plain axial and coronal slices with multi planar reformations.

Results: The reported findings were correlated with clinical and surgical findings in subset of cases. Sensitivity, Specificity of HRMDCT with respect to clinical and surgical correlation in selective cases was evaluated. Among 30 surgical cases, most of them were atticoantral (53.4\%) followed by tubotympanic CSOM (46.6\%). On surgical correlation, HRCT has a high sensitivity (84.36\%), specificity (80\%), PPV of $90.4 \%$ and accuracy of $90 \%$ in the diagnosis of type of CSOM. A significant association with $\mathrm{p}$ value $<0.05$ was seen for cholesteatoma, ossicle, bone, masotoiditis, scutum, tegmen and prussack space involvement. HRCT had a high sensitivity and specificity in detection of cholesteatoma $(86.4 \%, 88.9 \%)$.

Conclusion: a good sensitivity, specificity of HRCT of temporal bone has a major role in the diagnosis of type of CSOM with respect to surgical correlation. HRCT of Temporal bone affords essential information regarding the disease extent, associated complications, aiding clinicians in deciding the appropriate surgical planning and management, thereby making HRMDCT an essential pre workup diagnostic tool.
\end{abstract}

Keywords: Temporal bone, Cholesteatoma, HRCT, Facial canal dehiscence.

\section{Introduction}

Chronic suppurative otitis media (CSOM) is a chronic inflammation of the tympanic cavity. It is characterized by discharging ear, hearing deficit and otalgia and is most commonly associated with inflammation of the mastoid air cells, due to its anatomical connection to the middle ear. It has the potential for intracranial extension and associated complications. CSOM and resultant hearing loss of $60 \%{ }^{1}$ remains a significant health problem. $60 \%$ patients with CSOM usually have cholesteatoma. ${ }^{1,2}$

The incidence of cholesteatoma was 3 per 100,000 in children and 9 per 100,000 in adults CSOM accounts for high number of intracranial complications ${ }^{2}$ Highest prevalence $>4 \%$ seen in India which needs urgent attention as it is a massive health problem ${ }^{1}$ Early identification is needed to adopt the appropriate surgical procedure and to prevent hearing loss and complication. Among the temporal bone pathologies, CSOM is the most common followed by trauma and neoplasm. However it is noticed at a later stage because of its late presentation and increased complications. $^{3}$

The petrous temporal bone is a complex structure with minute middle and inner ear structures. It is difficult to evaluate temporal bone with imaging modalities like conventional radiograph, routine CT of head and MRI, due to difficulty in terms of resolution by radiological imaging techniques and hence led to the development of High Resolution Multi-detector Computed Tomography (HRMDCT) in the 1980s as a diagnostic tool for the evaluation of $\mathrm{CSOM}^{3}$ HRMDCT is considered as an essential tool in the evaluation of middle ear pathology ${ }^{3}$ as it provides essential information about bony details and soft tissue density. ${ }^{4}$

Therefore the aim of this study was determine the diagnostic role of High Resolution Multi-detector Computed Tomography (HRMDCT) of temporal bone in the evaluation of Chronic Suppurative Otitis Media (CSOM) and to correlate intraoperative and HRCT findings in CSOM in selective cases. This study was undertaken to evaluate the extent and site of involvement of middle ear and mastoid air cells in patients with CSOM. To correlate HRMDCT temporal bone findings with per-operative and clinical findings in the subset of patients who undergo surgery. 


\section{Material and Methods}

In this prospective study, 57 cases with CSOM in the age group of $6-70$ years who were referred from ENT outpatient Department and further referred to Department of Radiodiagnosis were randomly selected for the study and evaluated following all the inclusion and exclusion criteria. After obtaining prior approval from institutional ethical committee the study was conducted from January 2018 to June 2019.

\section{Inclusion Criteria}

Patients of both sexes and all age groups presenting with CSOM to ENT outpatient Department and referred to Department of Radio diagnosis were randomly included in this study.

\section{Exclusion criteria}

Patients with history of previous surgery for CSOM, patients with a history of prior temporal bone trauma, patients with ear implants, patients with otitis externa and patients with vascular lesions.

As soon as the patient presented to the hospital, detailed clinical history, preliminary lab investigations and clinical examination were carried out and documented. Suspected cases with symptoms such as otorrhea, otalgia, hearing loss, clinical and otoscopic findings such as granulation tissue, retraction pockets, and tympanic membrane perforation were referred to Department of Radiodiagnosis for HRMDCT for further evaluation. All the study patients were thoroughly explained about the study procedure and after obtaining a written inform consent from each patient. Important clinical, otoscopic findings were recorded in the proforma.

In Radiodiagnosis department, each scan was obtained on a GE bright speed Multi12 16-section spiral/helical CT scanner. First, lateral topogram was taken followed by helical acquisition was done in axial, coronal and sagittal planes. $0.6 \mathrm{~mm}$ plain axial slices with multiplanar reformations and bone algorithm were done. The scan was performed from the level of inferior mastoid to arcuate eminence. The scanning angle was 30 degree to baseline and parallel to lateral semi-circular canal. The studies were performed with the mentioned parameters: $2 \mathrm{~mm}$ collimation, $120 \mathrm{kVp}, 140 \mathrm{mAs}$, a pitch of $0.8,15-\mathrm{cm}$ field of view and a 512 x 512 matrix.

The image data set was reconstructed into magnified axial, sagittal, and coronal images with $0.1 \mathrm{~mm}$ thickness at an interval of $0.312 \mathrm{~mm}$ with overlap. A window width of $4000 \mathrm{HU}$ was used. All images were studied and interpreted on the GE workstation using the source and multiplanar reformatted images. Contrast study was advised when intracranial complications were present /suspected.

The HRCT findings were reported, correlated and tabulated with clinical findings in the proforma.A subset of 30 patients who underwent surgery during this study period was considered for surgical correlation. All the intraoperative findings were collected and correlated with HRCT findings in the proforma. All cholesteatoma cases were histopathologically diagnosed.

Data Analysis was done in the form of proportion or percentage. Sensitivity and Specificity of MDHRCT, with respect to clinical and surgical correlation in selected cases were evaluated. Association between categorical variables tested by using chi - square test /Fischer exact test.Value $\mathrm{p}$ $(<0.05)$ were considered to be statistically significant. SPSS software was utilized for analysis of collected data.

\section{Results}

All radiological findings were tabulated and correlated with intra-operative findings. False positive, false negative, sensitivity, specificity and $\mathrm{P}$ value were statistically analysed and tabulated as shown in tables 1, 2 and3. Association between categorical variables was tested by using chi - square test Value p $(<0.05)$ were considered to be statistically significant.

Out of 57 cases(100\%) of CSOM, 45 patients $(78.9 \%)$ presented with otalgia followed by 38 patients $(66.6 \%)$ with ear discharge, 14 patients $(2.5 \%)$ with hearing loss, 4 cases(7\%) with facial palsy, 6 cases $(10.5 \%)$ with sinusitis, 5 patients $(8.5 \%)$ with adenoid inflammation, 2 cases $(3.5 \%)$ with postauricular swelling, 3 cases $(5.3 \%)$ with fever, 1 case $(1.7 \%)$ with neck rigidity, 21 cases $(46.6 \%)$ of otalgia, 17 cases $(44.7 \%)$ of ear discharge, 7 cases $(50 \%)$ of hearing loss, 5 cases $(83.3 \%)$ of sinusitis, 5 cases $(100 \%)$ of adenoid inflammation, 2 cases $(100 \%)$ of tinnitus and 1 case $(25 \%)$ of facial palsy were seen in tubotympanic CSOM. 24 cases of otalgia(53.3\%), 21 cases(55.3\%) of ear discharge, 7 cases $(50 \%)$ of hearing loss, 1 case of vertigo(100\%), 3 case $(75 \%)$ of facial palsy, 2 cases $(100 \%)$ of post auricular swelling, 3 cases $(100 \%)$ with fever, 1 case $(100 \%)$ with neck rigidity were seen in atticoantral CSOM. Out of $14(100 \%)$ clinically detected cases of hearing loss 10 cases $(71.4 \%)$ had conductive (CHL) and 4 cases $(28.4 \%)$ had sensorineural hearing loss (SNHL). Out of the patients with hearing loss, conductive hearing loss was seen in 5 cases $(50 \%)$ of atticoantral and tubotympanic CSOM each. Sensorineural hearing loss was seen in 3 cases of 
atticoantral (75\%) and one case (25\%) of tubotympanic CSOM (Table 1).

Among the 30 surgical cases, most of them were atticoantral (53.4\%) followed by tubotympanic CSOM $(46.6 \%)$. On surgical correlation, HRCT has a high sensitivity of $84.36 \%$, specificity of $80 \%$, Positive Predictive Value (PPV) of $90.4 \%$ and accuracy of $90 \%$ in the diagnosis of type of CSOM. It had less Negative Predictive Value (NPV) of $72.7 \%$ due to the false negatives. $\mathrm{P}$ value $(<0.05)$ was considered to be statistically significant (Table2). A significant association with $\mathrm{p}$ value $<0.05$ was seen for cholesteatoma, ossicle, bone, masotoiditis, scutum, tegmen and prussack space involvement. HRCT had a high sensitivity and specificity in the detection of cholesteatoma $(86.4 \%, 88.9 \%)$, overall bone erosion $(89.3 \%, 91.6 \%)$, incus erosion $(83.3 \%, 100 \%)$, Prussack space involvement $(92.8 \%, 100 \%)$, tegmen erosion $\quad(100 \%, 100 \%), \quad \operatorname{scutum}(95 \%, \quad 100 \%)$, semicircular canal erosion $(80 \%, 100 \%)$, mastoiditis, tympanic membrane perforation $(81.8 \%, 85.7 \%)$, intracranial complications $(83.3 \%, 100 \%) \quad$ like osteomyelitis, cerebellar abscess and petrous apicitis. HRCT had moderate sensitivity in detecting overall ossicular erosion(76\%), malleus(60\%), stapes $(72.3 \%)$, sinus tympani(66.6\%), facial canal(69.2\%), attic/aditus/antrum (70-75\%), dural plate(75\%) and sigmoid plate(66.6\%)involvement(Table3).

\section{Discussion}

In our study, a majority of 45 patients (78.9\%) presented with otalgia. It was followed by 38 patients (66.6\%) with ear discharge, 14 patients $(24.5 \%)$ with hearing loss, 4 cases (7\%) with facial palsy, 6 cases $(10.5 \%)$ with sinusitis, and 5 cases $(8.7 \%)$ with adenoid inflammation. These findings were comparable to earlier study results. ${ }^{5,6,13}$ with similar features reported with otalgia, being most common followed by ear discharge and hearing loss.

In our present study, out of $30(100 \%)$ operated cases (Gold standard), 19 cases were atticoantral CSOM and 11 cases were tubotympanic CSOM intraoperative. 16 cases were atticoantral $(53.4 \%)$ and 14 cases $(46.6 \%)$ were diagnosed as tubotympanic CSOM on HRCT. Accordingly, out of the operated cases atticoantral CSOM was seen in majority with 16 cases $(53.4 \%)$ similar to the findings of Payal S et al ${ }^{5}$ and CL Thukral et $\mathrm{al}^{6}$ studies. HRCT had a sensitivity of $84.4 \%$, specificity of $80 \%$, Positive Probability Value (PPV) of 90.4\%. Negative Probilitity Value (NPV) of $72.7 \%$ was due to the false negatives. Sunitha Dashottaret $\mathrm{al}^{7}$ study had good NPV, but low specificity. However, Mariam Aljehaniet al ${ }^{8}$ study had
$100 \%$ sensitivity and specificity. $100 \%$ sensitivity and 95\% specificity was seen in Prabhu et $\mathrm{al}^{2}$ study.

The accuracy of HRCT was $90 \%$ in this study similar to Prabhu et $\mathrm{al}^{2}$ study with accuracy of $95 \%$ and the results showed a significant association with $\mathrm{p}$ value $0.16(p<0.05)$ and chi square statistic of 12.4 was seen for cholestestoma, bone erosion, ossicular erosion, mastoiditis, tegmen, scutum and prussack space involvement. These results were comparable with other studies. ${ }^{9}$

The study also showed that out of 30 operated cases, 19 cases had cholesteatoma out of which 16 were detected by HRCT. The two false positives were likely due to non cholesteatomatous atticoantral disease as quoted in their review article ${ }^{10}$. Most of the false positives were due to inability to differentiate granulation tissue from cholesteatoma or non cholesteaomatous type of atticoantral CSOM as quoted by Walsh et $\mathrm{al}^{11}$ in their study. Two cases of false negatives were found in mesotympanum followed by hypo tympanum( 1 case). Most of the false negatives were seen in mesotympanum with a sensitivity of $70 \% .^{12}$ and Hypotympanum soft tissue density has less sensitivity of $68 \%$ in a similar study ${ }^{13}$.

In the present study HRCT showed a high sensitivity of $86.4 \%$ and specificity of $88.9 \%$ in detecting the cholesteatoma/atticoantral disease. Our results were comparable with previous study. ${ }^{9}$ But a high sensitivity (100\%) and specificity (95\%) were reported in similar previous studies. ${ }^{2,4,7}$ However, Wang EL et al ${ }^{14}$ study showed less sensitivity (65\%) and specificity (72\%) in identifying cholesteatoma and they stated that it was due to HRCT inability to differentiate it from soft tissue density based on Hounsfield Units (HU) value alone. Vinith Kumar Sharma et $\mathrm{al}^{15}$ in their study quoted that HRCT is less accurate in differentiating the granulation tissue from cholesteatoma and requires clinical correlation. Bone erosion was seen in 25 cases intra operatively of which 22 cases were detected by HRCT. The two false positives were present in tubotympanic CSOM. False negatives ( 2 cases) were seen in tubotympanic type, and were seen in ossicle involvement. Hence, HRCT had a high sensitivity of $89.3 \%$ and specificity of $91.6 \%$ in detecting the bone erosion. These findings are comparable with previous study ${ }^{13}$ which showed high sensitivity $80 \%$ and specificity $100 \%$ respectively.

Similarly, ossicular erosion was seen in 19 cases intra operatively of which 13 cases were detected by HRCT in the present study. Two false positives were present in tubotympanic CSOM. Majority of false negatives (4 cases) were seen in tubotympanic type. 
Hence HRCT had less sensitivity of $76 \%$ but high specificity of $86.6 \%$ in detecting the ossicular erosion and these findings are in concurrence with earlier study. ${ }^{16}$

HRCT has shown a less sensitivity $72.3 \%$ but high specificity $83.3 \%$ in the detection of stapes erosion. One false positive was seen involving supra structure of stapes. Majority of false negatives ( 2 cases) had foot plate erosion. Payal $\mathrm{G}$ et $\mathrm{al}^{17}$ quoted that the false negatives were due to tissue partial volume averaging phenomenon and soft tissue around the supra structure of stapes makes it difficult to visualize. Their study also quoted that foot plate of stapes has poor visualization. Sunita Dashottar et $\mathrm{al}^{7}$ in their study had less sensitivity of $68 \%$. Whereas Poor kappa value of 0.3-0.5 was seen in Zhang $\mathrm{X}$ et $\mathrm{al}^{18}$ study and Sonika et $\mathrm{al}^{12}$ study had good sensitivity $90 \%$ and $100 \%$ specificity.

In our study, HRCT has shown a high sensitivity $83.3 \%$ and specificity $100 \%$ in the detection of incus erosion with no false positives being present similar to other study findings ${ }^{9}$ with sensitivity $85.7 \%$ and $100 \%$ specificity. However, false negatives (2 cases) were seen involving lentiform process in majority. Payal G et $\mathrm{al}^{17}$ in their study quoted that most of the false negatives involved the lentiform process which is the most common site of ossicular erosion and is a subtle finding.

In the detection of malleus erosion. HRCT has less sensitivity $60 \%$ and specificity $85.7 \%$. One false positive was seen involving manubrium/handle of malleus. False negatives were seen involving manubrium (4 cases) followed by lateral process (2cases) and head (1 case). Sunitha Dashottar ${ }^{7}$ and KarkhiS et $\mathrm{al}^{20}$ had a sensitivity of $60 \%$. However, in Tripthi Rai ${ }^{13}$ study, good sensitivity $100 \%$ and specificity $100 \%$. Amy $\mathrm{F}$ Julianoet $\mathrm{al}^{21}$ in their study quoted most often the manubrium of malleus are early sites of cholesteatoma erosion and is a subtle finding.

Prussack space involvement was seen in 13 cases out of which 12 cases were detected by HRCT. False negative was seen associated with soft tissue density in mesotympanum (pars tensacholesteatoma). HRCT has a high sensitivity $92.8 \%$ and specificity $100 \%$ in the detection of prussack space involvement. Similar results were seen in HassmannPoznanaskaet $\mathrm{al}^{22}$ study with sensitivity of $87 \%$ and specificity of $100 \%$ and the false negatives were due to pars tensacholesteatoma with marginal perforation. Bernadette Koch et $\mathrm{al}^{23}$ in their book have quoted that Prussack space involvement less commonly occurs in pars
HRCT has a high sensitivity $95 \%$ and specificity $100 \%$ in the detection of scutum erosion where in Scutum erosion was seen in 19 cases of which 18 cases were detected by HRCT. False negative was seen associated with soft tissue density in mesotympanum (pars tensacholesteatoma). A similar study ${ }^{7}$ had reported high sensitivity and specificity values, explaining scutum involvement was most commonly seen in early atticoantral disease and is most commonly associated with pars flaccidacholesteatoma. Bernadette Koch et $\mathrm{al}^{23}$ in their book have quoted that scutum erosion occurs less commonly occurs in pars tensacholesteatoma.

All 12 cases detected tegmen erosion on HRCT showing high sensitivity and specificity of $100 \%$. These findings are in concurrence with other studies ${ }^{24}$. However, in Mardassi Ali et al ${ }^{16}$ study had poor sensitivity of $60 \%$ and were mostly seen in pars tensacholesteatoma unlike $70 \%$ sensitivity reported in Prabhu et $\mathrm{al}^{2}$ study. Studies ${ }^{17}$ quoted that tegmen and dural plate erosion helps to decide surgical approach based on tympanic membrane and compartment involved.

Sinus tympani involvement was seen in 2 cases of which 1 case was detected on HRCT and thereby HRCT has less sensitivity $66.6 \%$ in the detection of sinus tympani involvement. These findings are in ordinance with another study. ${ }^{17}$ with sensitivity of $72 \%$. The true positive was seen associated with mesotympanum soft tissue density (pars tensacholesteatoma) and false negative was seen associated with epitympanum soft tissue density (parsflaccidacholesteatoma). Most of the false negatives were seen in pars flaccidacholesteatoma in other similar studies ${ }^{17}$. They quoted that sinus tympani is a delicate structure and difficult to visualize in the presence of cholesteatoma. But review articles ${ }^{25,26}$ quoted sinus tympani involvement was most common in pars tensacholesteatoma and is a common site of residual/recurrent cholesteatoma.

In the present study 5out of 9 cases of facial canal dehiscence were detected on HRCT with less sensitivity $69.2 \%$ and good specificity $80 \%$. Unlike in other studies ${ }^{2,16}$ had poor sensitivity, Zhang $\mathrm{X}$ et al $^{18}$ had a low kappa value of (0.3-0.5) with poor sensitivity. In our study, false negatives in facial canal dehiscence were seen associated with soft tissue density in mesotympanum(pars tensacholesteatoma) in majority and 1 case in tubotympanic CSOM and most of the false negatives involved vertical segment of facial canal. One false positive was seen associated with mesotympanum soft tissue density (parstensacholesteatoma) which involved the tympanic 
segment of facial nerve. Studies ${ }^{24}$ quoted that tympanic segment of facial nerve canal and part of vertical segment was most commonly missed due to the thin underlying bony floor. But mesotympanum soft tissue density usually makes it difficult to identify facial canal dehiscence due to the oblique orientation of scan and it is frequently difficult to locate the pathology ${ }^{6,26}$.

Semi-circular canal erosion was seen in 4 cases intra operatively out of which 3 cases were diagnosed by HRCT. HRCT has a high sensitivity of $80 \%$ and specificity $100 \%$ in the detection of semi-circular canal erosion. Zhang $\mathrm{X}$ et a ${ }^{18}$ had good kappa value of $0.5-7$. M D Prakashet al ${ }^{24}$ study had a sensitivity of $75 \%$ and specificity of $100 \%$. In our study, one false negative in semi-circular canal erosion was seen associated with pars tensacholesteatoma. Bernadette Koch et $\mathrm{al}^{23}$ in their book have quoted that semicircular erosion occurs more commonly in pars tensacholesteatoma and can be masked by mesotympaum soft tissue density. False negative was seen involving lateral and posterior semi-circular canal erosions. Sonika et $\mathrm{al}^{12}$ in their study had most of the false negatives involved the lateral semi-circular canal with a low sensitivity of $66.6 \%$ and lowest $25 \%$.

In our study, 19 cases had mastoiditis intra operatively out of which 18 cases were detected on HRCT. HRCT has a high sensitivity $95 \%$ and high specificity $100 \%$ in the detection of mastoiditis. Automastoidectomy was detected with $100 \%$ sensitivity. These findings were comparable with other studies ${ }^{12}$ had $100 \%$ sensitivity and specificity in detecting mastoiditis. False negative was seen in coalascentmastoiditis in atticoantral type. A review article $^{25}$ mentioned that coalascentmastoiditis is more commonly seen in atticoantral/complicated mastoiditis. Sasmita et $\mathrm{al}^{20}$ had good sensitivity in the detection of automasoidectomy.

In our study, HRCT had less sensitivity $75 \%$ and high specificity $85.7 \%$ in the detection of tympanic perforation. Hassmann Poznanaskaet $\mathrm{al}^{22}$ in their study had a similar sensitivity (84\%) and specificity (86\%). In our study, majority of false negatives was seen in pars flaccid cholesteatoma with marginal perforation followed by tubotympanic CSOM. Similar findings were identified in other studies ${ }^{24,23}$. False positives (2 cases) were also seen with pars flaccidacholesteatoma (marginal perforation). Mariam Alijehani et $\mathrm{al}^{8}$ quoted that most of the false positives were due to prussack space involvement by cholesteatoma making it difficult to identify marginal perforations. False negatives in perforation were due to non-visualization either due to polyp or sagging meatal wall ${ }^{9}$. HRCT in the present study has shown less sensitivity $72.2 \%$ and high specificity $100 \%$ in the detection of attic involvement. Majority false negatives were seen in tubotympanic followed by pars flaccidaatticoantral CSOM. Sunitha Dashottar et $\mathrm{al}^{7}$ had a sensitivity of $50 \%$ and specificity $83 \%$ in their study. In a review study $^{25}$ they have quoted that attic/aditus and antrum involvement can be seen in both pars tensa and pars flaccidacholesteatoma and can also be seen in tubotympanic CSOM.

In our study, HRCT has a less sensitivity $72.7 \%$ and high specificity $100 \%$ in the detection of aditus erosion. False negatives, (4 cases) were seen majority in atticoantral CSOM with pars flaccidacholesteatoma. Nanjaraj CP et $\mathrm{al}^{9}$ had a $92 \%$ sensitivity and $91 \%$ specificity. In our study, 15 cases had antrum involvement intra operatively with 10 cases detected on HRCT. HRCT has less sensitivity $75 \%$ and specificity $100 \%$ in the detection of antrum erosion. False negatives (4 cases) were seen majority in tubotympanic CSOM. A similar sensitivity of $88 \%$ was seen in Tripathi Rai ${ }^{13}$ study.

Present study showed 4 cases of sigmoid plate erosion intra operatively out of which 2 cases were detected on HRCT. HRCT has $66.6 \%$ sensitivity and $100 \%$ specificity in the detection of sigmoid plate erosion. 2 False negatives were seen in atticoantral CSOM with cholesteatoma involving more than one compartment. These findings were similar to earlier study ${ }^{24}$ had a sensitivity of $85.7 \%$. Mariam Aljehani et $\mathrm{al}^{8}$ in their study had $100 \%$ sensitivity and specificity and they also quoted that sigmoid plate erosion was seen most commonly with large cholesteatoma with extensive bony destruction.

Out of 5 cases with intracranial complications, 4 cases were detected on HRCT thereby exhibiting sensitivity $83.3 \%$ and specificity of $100 \%$ and these findings are similar with other studies ${ }^{9,13} .80 \%$ of the intracranial complications were present in atticoantral CSOM, similar to Nanjaraj CP et $\mathrm{al}^{9}$ study with $100 \%$. One false negative was seen in detection of petrous apicitis in tubotympanic CSOM with sclerosed mastoids. A review article ${ }^{25}$ reported petrous apicitis is more common in sclerosed mastoids and tubotympanic CSOM. In our study the most common intracranial complication was petrous apicitis $3.5 \%$ followed by cerebellar abscess $1.7 \%$, meningitis $1.7 \%$ and skull base osteomyelitis (1.7\%). But other studies have noted sub periosteal abscess $(8 \%)$ was the most common intracranial complication ${ }^{13}$ and $4 \%$ had brain abscess and mastoid abscess which were the other most common intracranial complications followed by temporal lobe abscess(2\%) and skull base 
osteomyelitis( $2 \%)$. In the present study, among the surgical cases, most of them were atticoantral followed by tubotympanic CSOM and HRCT has shown high sensitivity, specificity and PPV in the diagnosis of CSOM.

Table 1: Clinical Features Distribution and its HRCT Correlation in CSOM

\begin{tabular}{|c|c|c|c|}
\hline Total & $57(100 \%)$ & Tubo tympanic & Attico antral \\
\hline Otalgia & $45(78.9 \%)$ & $21(46.6 \%)$ & $24(53.3 \%)$ \\
\hline Ear discharge & $38(66.6 \%)$ & $17(44.7 \%)$ & $21(55.3 \%)$ \\
\hline Hearing loss & $14(24.5 \%)$ & $7(50 \%)$ & $7(50 \%)$ \\
\cline { 2 - 4 } CHL & $10(71.4 \%)$ & $5(50 \%)$ & $5(50 \%)$ \\
SNHL & $4(28.5 \%)$ & $1(25 \%)$ & $3(75 \%)$ \\
\hline Sinusitis & $6(10.5 \%)$ & $5(83.3 \%)$ & $1(16.7 \%)$ \\
\hline Adenoid Inflammation & $5(8.7 \%)$ & $5(100 \%)$ & \\
\hline Tinnitus & $2(3.5 \%)$ & $2(100 \%)$ & $1(100 \%)$ \\
\hline Vertigo & $1(1.7 \%)$ & & $3(75 \%)$ \\
\hline Facial nerve palsy & $4(7 \%)$ & $1(25 \%)$ & $2(100 \%)$ \\
\hline Post auricular swelling & $2(3.5 \%)$ & & $2(100 \%)$ \\
\hline Fever & $3(5.3 \%)$ & & $1(100 \%)$ \\
\hline Neck rigidity & $1(1.7 \%)$ & & \\
\hline
\end{tabular}

Table 2: HRCT and surgical correlation for diagnosis of type of CSOM

\begin{tabular}{|c|c|c|c|}
\hline Accuracy -90\% & Tubo Tympanic & Attico Antral & Total \\
\hline Intra operative & $11(36.6 \%)$ & $19(63.3 \%)$ & $30(100 \%)$ \\
\hline HRCT & $14(46.6 \%)$ & $16(53.4 \%)$ & $30(100 \%)$ \\
\hline Sensitivity -84.4\% & Specificity- $80 \%$ & PPV- $90.4 \%$ & NPV- $72.7 \%$ \\
\hline
\end{tabular}

Out of $30(100 \%)$ operated cases (Gold standard), 19 cases were atticoantral CSOM of which 16 cases (53.4\%) were correctly diagnosed by HRCT. Intra operatively, 11 cases were tubo tympanic whereas on HRCT 14 cases (46.6\%) were diagnosed as tubotympanic CSOM. Therefore HRCT has a Sensitivity of $84.4 \%$, Specificity of $80 \%$, PPV of $90.4 \%$, NPV of $72.7 \%$ and accuracy of $90 \%$ in the diagnosis of type of CSOM.

Table 3: Correlation between HRCT and intraoperative findings in CSOM

\begin{tabular}{|l|c|c|c|c|c|c|}
\hline \multicolumn{1}{|c|}{ Findings } & $\begin{array}{c}\text { HRCT } \\
\mathbf{3 0}(\mathbf{1 0 0 \%})\end{array}$ & $\begin{array}{c}\text { Intraope } \\
\text { rative }\end{array}$ & $\begin{array}{c}\text { False } \\
\text { Positive }\end{array}$ & $\begin{array}{c}\text { False } \\
\text { Negative }\end{array}$ & Sensitivity & Specificity \\
\hline Cholesteatoma & $16(53.3 \%)$ & 19 & 2 & 3 & $86.4 \%$ & $88.9 \%$ \\
\hline Bone Erosion & $22(73.3 \%)$ & 25 & 2 & 3 & $89.3 \%$ & $91.6 \%$ \\
\hline Mastoiditis & $18(60 \%)$ & 19 & & 1 & $95 \%$ & $100 \%$ \\
\hline Ossicle Erosion & $13(43.3 \%)$ & 19 & 2 & 6 & $76 \%$ & $86.6 \%$ \\
\hline Malleus Erosion & $6(20 \%)$ & 13 & 1 & 7 & $60 \%$ & $85.7 \%$ \\
\hline Incus Erosion & $12(40 \%)$ & 15 & - & 3 & $83.3 \%$ & $100 \%$ \\
\hline Stapes Erosion & $5(16.6 \%)$ & 8 & 1 & 3 & $72.3 \%$ & $83.3 \%$ \\
\hline Tegmen Erosion & $12(40 \%)$ & 12 & - & - & $100 \%$ & $100 \%$ \\
\hline Scutum Erosion & $18(60 \%)$ & 19 & - & 1 & $95 \%$ & $100 \%$ \\
\hline Prussack Soft Tissue Density & $12(40 \%)$ & 13 & - & 1 & $92.8 \%$ & $100 \%$ \\
\hline Sinus tympani Involvement & $1(3.3 \%)$ & 2 & - & 1 & $66.6 \%$ & $100 \%$ \\
\hline Tympanic membrane Perforation & $12(40 \%)$ & 18 & 2 & 6 & $81.8 \%$ & $85.7 \%$ \\
\hline Facial Canal dehiscence & $5(16.6 \%)$ & 9 & 1 & 4 & $69.2 \%$ & $80 \%$ \\
\hline Semi-circular canal Erosion & $3(10 \%)$ & 4 & - & 1 & $80 \%$ & $100 \%$ \\
\hline & HRCT & Intra & False & False & Sensitivity & Specificity \\
\hline Lateral Semi-circular Canal Erosion & $30(100 \%)$ & operative & Positive & Negative & & \\
\hline $\begin{array}{l}\text { Posterior Semi-circular Canal } \\
\text { Erosion }\end{array}$ & $1(10 \%)$ & 4 & - & 1 & $80 \%$ & $100 \%$ \\
\hline
\end{tabular}




\begin{tabular}{|l|c|c|c|c|c|c|}
\hline $\begin{array}{l}\text { Superior Semi-circular Canal } \\
\text { Erosion }\end{array}$ & $1(3.3 \%)$ & 1 & - & - & $100 \%$ & $100 \%$ \\
\hline Attice Involvement & $8(26.6 \%)$ & 13 & - & 5 & $72.2 \%$ & $100 \%$ \\
\hline Aditus Involvement & $10(33.3 \%)$ & 16 & - & 6 & $72.7 \%$ & $100 \%$ \\
\hline Antrum Involvement & $10(33.3 \%)$ & 15 & - & 5 & $75 \%$ & $100 \%$ \\
\hline Cerebellar Abscess & $1(3.3 \%)$ & 1 & - & - & $100 \%$ & $100 \%$ \\
\hline Sigmoid Plate Erosion & $2(6.6 \%)$ & 4 & - & 2 & $66.6 \%$ & $100 \%$ \\
\hline Petrous Apicitis & $1(3.3 \%)$ & 2 & - & 1 & $66.6 \%$ & $100 \%$ \\
\hline Osteomyelitis & $1(3.3 \%)$ & 1 & - & - & $100 \%$ & $100 \%$ \\
\hline Intracranalcomplications & $4(7 \%)$ & 5 & - & 1 & $83.3 \%$ & $100 \%$ \\
\hline
\end{tabular}

A significant association with $\mathrm{p}$ value $\mathbf{0 . 0 1 6}(\mathrm{p}<0.05)$ and chi square statistics of 12.4 was seen for cholestestoma, bone erosion, ossicular erosion, mastoiditis, tegmen, scutum and prussack space involvement.

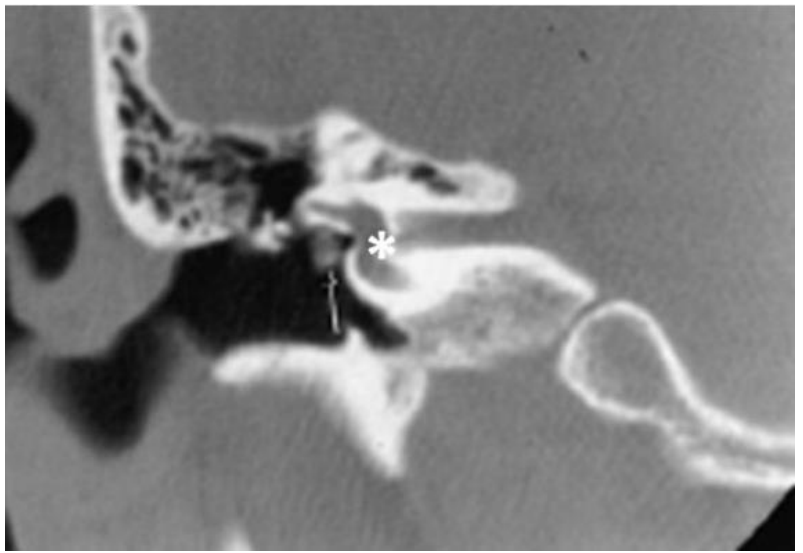

Fig. 1: Coronal Image- Facial canal dehiscence. Defect noted in tymanic segment of facial canal suggestive of facial canal dehiscence.*

\section{Conclusion}

HRCT Temporal bone has a good sensitivity, specificity and accuracy in the diagnosis of type of CSOM with respect to surgical correlation (Gold standard). It helps in detection of soft tissue density in middle ear and mastoid with great precision, its location and relation to adjacent structures. It has high sensitivity and specificity in the detection of cholesteatoma, ossicular and other bony erosions and intracranial complications.

However, it faces its own challenges in the characterization of soft tissue density, facial canal dehiscence and tympanic membrane perforation. HRCT Temporal bone provides a great deal of information which is extremely useful for confirming the diagnosis of CSOM, treatment planning and surgical approach, making it an essential pre work up diagnostic tool and a road map for surgery.

Hence, this study suggests that HRCT of Temporal Bone should be recommended as a diagnostic aid for all cases of CSOM to evaluate its extent, possible complications of the disease and for appropriate management.

\section{Source of funding \\ None.}

\section{Conflict of interest}

None.

\section{References}

1. Keskin S, Cetin H. The correlation of temporal bone CT with surgery findings in evaluation of chronic inflammatory diseases of the middle ear. Eup J Gen Med 2011; 8(1):24-30.

2. Khavasi P, Malashetti S, Chandrashekarayya. An evaluation of pre-operative High Resolution Computedn Tomography of the Temporal Bone in Cholesteatoma. Int $J$ Otorhinolaryngol Head Neck Surg 2018;4(2):413-7.

3. Poursadegh M, Hashemi G. Evaluation of Anatomical variations of vestibular aqueduct dimensions in temporal bone CTscan. MJIRI 2000;14(3):199-202.

4. Haaga JR, Bell D T. 'Temporal Bone'. Chapter 21, CT and MRI of whole body.6th edition. Elsevier India; 2016:614650.

5. Payal S Chavada, Manish R. Middle Ear Cholesteatoma: A study of correlation between HRCT temporal bone and intraoperative surgical findings. Intl J Otorhinolarongology 2018;4(5):1252-57.

6. CL.Thukral et al. Role of high resolution computed tomography in evaluation of pathologies of temporal bone. J Clin Diagn Res 2015;1-9(9):TC07-TC10.

7. Dwaraknath K. Sirigiri RR. Correlative Study of HRCT in Attico-Antral Disease. Indian J Otolaryngol Head Neck Surg 2011;63:155-8.

8. Alhussini R. Jumaily ZH. The correlation Between Computed Tomography (HRCT) and intra operative findings of Chronic otitis media. Clin Medl Insight Ear Nose Throat 2019;12:1-52.

9. Nanjaraj CP, Nagarajegowda PH, Kannan VP, PKC Nagarajiah. Chronic otitis media: High resolution computed tomographic evaluation of the temporal bone with surgical correlation. J Evid Based Med Healthc 2016;3(40):1955-62.

10. AshuSeithBhalla, Anuradha Singh, Manisha J. Chronically discharging ears: Evaluation with high resolution computed tomography. Polish J Radiol 2017;82:478-89. 
11. Walsch P, R Mc Conn Walsh. The role of computerised tomography in the pre-operative assessment of chronic otitis media. Clin Otolaryngol 2002;27(2):95-7.

12. Kanotra S, Gupta R. Correlation of high resolution computed tomography temporal bone findings with intra operative findings in patients with cholesteatoma. Ind JOtology 2015;21(4):280-5.

13. Rai T. Radiological study of the temporal bone in chronic otitis media -Prospective study of 50 cases. Ind J Otology 2019;20(2):48-55.

14. Wang EL, Gu F. Significance of CT in the diagnosis of Chronic Suppurative Otitis Media. J Chinese Med 2007;42(7):494-8.

15. Sharma VK, Prajapathi N. Radiological changes in anatomy of temporal bone in cases of unsafe chronic suppurative otitis media- A prospective Study. IndJ Otology 2017;23(3):176-9.

16. Ali M, Nabi M. Limits of conventional temporal bone computed tomography in the management of cholesteatoma otitis media - Report of 96 cases. Egyp J Otolaryngol 2014;30(2):73-77.

17. Payal G. Computed Tomography in Chronic Suppurative Otitis Media: Value in Surgical Planning. Indian J Otolaryngol Head Neck Surg 2012;64:225-40.

18. Zhang X, Chen Y. CT scan verses surgery: How reliable is the pre-operative radiological assessment in patients with chronic otitis media. J Chinese Med 2004;18(7):396-83.

19. SasmitaPravat,Pravat N R. Role of HRCT in temporal bone Diseases: A study of 100 cases. Www/jkscience.org. 2018;20(1):34-8.
20. Karki S, Pokharel M. Correlation between pre-operative High Resolution Computed Tomography (CT) Findings with Surgical findings in chronic otitis media squamous type. J Kathmandu Med Univ 2017; 579(10):83-6.

21. Amy F Juliano. Imaging Review of the Temporal Bone: Part I. Anatomy and Inflammatory and Neoplastic Processes. Radiol RSNA 2013;269:17-33

22. HassmannPoznanska et al. Computerized Tomography in pre-operative imaging of middle ear cholesteatoma. $J$ Otolaryngol Pol 2003;57(2):243-9.

23. Bernadette Koch, Bronwyn E Hamilton, Patricia Hudgins, H Richarnsberger. Imaging of Temporal Bone,Section 25, Diagnostic Imaging: Head and Neck. $3^{\text {rd }}$ edition. Elsevier India; 2017:1041-59.

24. Prakash M.D, AfshanTarannum. Role of High Resolution Computed Tomography of Temporal Bone in Pre-operative Evaluation of Chronic Supparative Otitis Media. Int J Otorhinolaryngol Head Neck Surg 2018;4(5):1287-92.

25. AshuSeithBhalla, Anuradha Singh, Manisha J. Chronically discharging ears: Evaluation with high resolution computed tomography. Polish J Radiol 2017;82:478-89.

How to cite: Pramod V, Raghuraj U, Shrikrishna U. Correlation of Intraoperative and HRCT of Temporal Bone Findings in CSOM. IP $J$ Otorhinolaryngol Allied Sci 2020;3(1):10-7. 